\title{
COMPORTAMENTO DE DOIS GENÓTIPOS DE MILHO CULTIVADOS EM SISTEMA DE ALÉIAS PREESTABELECIDO COM DIFERENTES LEGUMINOSAS ARBÓREAS ( $\left.{ }^{1}\right)$
}

\author{
ANDRÉIA ARAÚJO LIMA LEITE $\left({ }^{2}\right)$; ALTAMIRO SOUZA DE LIMA FERRAZ JUNIOR $\left({ }^{2}\right)$; \\ EMANOEL GOMES DE MOURA $\left({ }^{2 *}\right)$; ALANA DAS CHAGAS FERREIRA AGUIAR $\left({ }^{3}\right)$
}

\begin{abstract}
RESUMO
O cultivo em aléias tem sido recomendado como alternativa para a substituição da agricultura de corte e queima, no trópico úmido, devido à grande capacidade de produção de matéria orgânica e de reciclagem de nutrientes, mas algumas dúvidas quanto à sustentabilidade e à competição interespecífica são persistentes. O objetivo no trabalho foi avaliar a viabilidade da cultura do milho em um sistema de cultivo em aléias de leguminosas arbóreas. O delineamento experimental utilizado foi em blocos casualisados, com quatro repetições dos tratamentos: aléias de sombreiro (Clitoria fairchildiana), ingá (Inga edulis), guandu (Cajanus cajan) e leucena (Leucaena leucocephala) e uma testemunha sem aléias. Foram avaliadas a remobilização de carbono e nitrogênio, massa de grãos, massa de mil grãos e competição interespecífica entre as cultivares de milho e as leguminosas. A produção de grãos foi maior nas parcelas com C. fairchildiana e L. leucocephala. A produtividade do híbrido de milho foi superior à da variedade em todos os tratamentos. A produtividade e a massa de mil grãos de milho não são negativamente afetadas pela distância da linha da leguminosa arbórea. Esse estudo conclui que o sistema de aléias com leguminosas arbóreas é uma alternativa importante ao manejo sustentável dos agroecossistemas no tropico úmido. Além disso, nessa região a produtividade em grãos na cultura do milho é favorecida no sistema de aléias preeestabelecidas com as leguminosas arbóreas sombreiro, ingá e leucena e pela utilização de genótipos eficientes no aproveitamento do nitrogênio, cujo sincronismo entre a liberação e a absorção do $\mathrm{N}$ aplicado por meio das leguminosas deve ser aprimorado.
\end{abstract}

Palavras-chave: Zea mays, sustentabilidade, produtividade, sincronismo.

\section{ABSTRACT \\ BEHAVIOUR OF TWO MAIZE GENOTYPES GROWN IN ALLEY CROPPING SYSTEM PRE-ESTABLISHED WITH DIFERENTS LEGUMINOUS TREES}

Alley cropping has been recommended as alternative land use to slash-and-burn agriculture in humid tropics. However, interespecific competition between cash crop and hedgerow can reduce this potential. This study aimed to evaluate the feasibility of maize crop in a leguminous tree alley cropping. A random block experimental design was adopted, with four replicates and five treatments: alleys of "sombreiro" (Clitoria fairchildiana), inga (Inga edulis), pigeon pea (Cajanus cajan), and leucaena (Leucaena leucocephala) and a control treatment without alley. C and N partitioning, grain yield, 1000 grain mass and interspecifics competition between maize varieties and legume hedgerows were evaluated. Grain yield was higher for C. fairchildiana and L. leucocephala treatments. The grain yield of hibrid maize was higher than that of maize variety at all treatments. The grain yield and 1000 grain mass maize was not affected by distance of legume hedgerows. This study concluded that the alley cropping with leguminous tree is an important alternative to the sustainable management of agroecosystems in humid tropics. Furthermore, in this region, the productivity of maize grain is favored in alley cropping with leguminous trees, like sombreiro, inga and leucena by genotypes efficient in the use of nitrogen, whose timing between its release and absorption when applied by means of pulses, must be enhanced.

Key words: Zea mays, sustainability, productivity, synchrony.

$\left({ }^{1}\right)$ Parte da Dissertação de Mestrado, Curso de Agroecologia, da primeira autora, apresentada à Universidade Estadual do Maranhão, São Luís (MA). Recebido para publicação em 23 de fevereiro de 2006 e aceito em 3 de maio de 2008.

$\left({ }^{2}\right)$ Programa de Pós-Graduação em Agroecologia, Caixa Postal 3004, 65054-970 São Luís (MA). E-mail:egmoura@elo.com.br (*) Autor correspondente.

(3) Centro de Ciências Agrárias e Ambientais,Universidade Federal de Maranhão, BR 22, Km 04, 65000-000 Chapadinha (MA). E-mail: alanaaguiar@elo.com.br 


\section{INTRODUÇÃO}

As condições sócioambientais no trópico úmido representam grande desafio para a pesquisa agropecuária, principalmente porque se associam, em uma mesma região, solos de reduzida fertilidade natural, elevada precipitação pluvial e o modelo itinerante de uso da terra, em que se utiliza o sistema de corte e queima entre períodos de pousios cada vez mais curtos e insuficientes para a recuperação do equilíbrio do sistema. Nestas condições, tem-se apenas desvantagem porque é afetada a biodiversidade, contribuindo-se para o aumento da produção de gases do efeito estufa, sem diminuição da pobreza no meio rural. Dentre as alternativas para o uso sustentável do solo na região devem-se incluir a cobertura da superfície, com a adição continuada de resíduos vegetais, a manutenção ou aumento da matéria orgânica do solo, e a ciclagem de nutrientes (FERRAZ JúNIOR, 2004).

No sistema de cultivo em aléias favorece-se a integração simultânea de todos estes processos, e por isso, pode-se contribuir para a solução de parte dos problemas de segurança alimentar de milhões de pessoas que vivem nos trópicos, com menos aplicações de insumos externos. Nesse sistema de cultivo combinam-se, em uma mesma área, espécies arbóreas - preferencialmente leguminosas e culturas anuais - visando ao mesmo tempo aos processos de regeneração da fertilidade do solo e de intensificação da ciclagem de nutrientes, os quais são temporariamente separados na agricultura de derrubada-queima-pousio (ATTA-KRAH, 1989; KANG et al., 1990).

No sistema de aléias com leguminosas o suprimento das exigências nutricionais da cultura principal não é dependente apenas das quantidades adicionadas a partir dos ramos, mas também da eficiência de transferência dos nutrientes do solo para as plantas, processo estreitamente relacionado à qualidade da matéria orgânica adicionada, aos organismos presentes no sistema e à eficiência de absorção de nutrientes pela planta (SWIFT e PALM, 1995). Com algumas práticas de manejo associadas ao uso de híbridos e de cultivares mais eficazes podese também aumentar a eficiência do uso de nutrientes (HuAng et al., 1996; VARVEL, 1994).

Nos solos do trópico úmido, sob elevadas temperaturas e chuvas intensas pode-se ter contribuição com o cultivo de algumas leguminosas arbóreas para a sustentabilidade dos sistemas agrícolas, por meio de grandes produções de matéria seca e da ciclagem de nutrientes, além da adoção de outras práticas, como o plantio direto e a cobertura morta, com as quais se obtém efeito positivo e significativo na produtividade das culturas, como constatado por Moura (1995) e Albuquerque (1999).

Para ampliar o conhecimento sobre o manejo de agroecossistemas no trópico úmido, este trabalho foi desenvolvido com a finalidade de se avaliar a viabilidade de um sistema de cultivo em aléias, preestabelecidos com leguminosas arbóreas, em Argissolo de textura franco-arenosa, no desempenho de variedades e de híbrido de milho.

\section{MATERIAL E MÉTODOS}

O experimento foi realizado em área experimental na Universidade Estadual do Maranhão, em São Luís (MA), situada a $44^{\circ} 18^{\prime}$ de longitude oeste e $2^{\circ} 30^{\prime}$ de latitude sul em um Argissolo VermelhoAmarelo distrófico, de textura franco-arenosa, em 2001.

O delineamento experimental utilizado foi o de blocos casualisados, com quatro repetições de tratamentos com leguminosas arbóreas: aléias de sombreiro (Clitoria fairchildiana), ingá (Inga edulis), guandu (Cajanus cajan) e leucena (Leucaena leucocephala) e de uma testemunha sem aléias, dispostos em esquema de parcelas subdivididas. As árvores foram previamente estabelecidas em 1996, com sementes distribuídas em linhas duplas alternadas, distantes $0,5 \mathrm{~m}$ entrelinhas e $0,5 \mathrm{~m}$ entre plantas, sendo podadas anualmente. As linhas duplas foram espaçadas de $4 \mathrm{~m}$, onde foram estabelecidas as parcelas de $4 \mathrm{~m} \times 14 \mathrm{~m}$. Em janeiro de 2001, as parcelas foram subdividas em duas subparcelas de $4 \mathrm{~m} \times 7 \mathrm{~m}$, onde se semearam dois genótipos de milho - o híbrido AG 405 e a variedade BR 106, em linhas espaçadas de $1 \mathrm{~m}$, com cinco sementes por metro, aplicando-se $300 \mathrm{~kg} \mathrm{ha}^{-1}$ da fórmula 05-25-20 na semeadura e 25 $\mathrm{kg} \mathrm{ha}^{-1}$ de N, na forma de uréia, em cobertura, aos 40 dias após a semeadura.

Nas fases fenológicas correspondentes à antese e à maturidade, foram coletadas duas plantas de milho por subparcela, e separadas em folhas, colmo e espigas no laboratório e, em seguida, submetidas à secagem para determinação da quantidade de matéria seca e dos teores de N, P, K, Ca, Mg, segundo Tedesco (1982).

$\mathrm{Na}$ colheita do milho, foram aleatoriamente amostradas 20 espigas/subparcela, sendo cinco espigas em cada uma das quatro linhas semeadas entre as leguminosas. Os dados das linhas adjacentes foram separados dos coletados nas linhas centrais para determinação da competição interespecífica. Os grãos foram separados das espigas e amostras de aproximadamente $70 \mathrm{~g}$ colocadas em estufa a $105^{\circ} \mathrm{C}$, para determinação do grau de umidade; os valores de produção de grãos foram padronizados a $11 \%$ de umidade. Foram determinados: 
- Massa de mil grãos;

- Índice de colheita de grãos (IC), IC= [MG/ (MG+MSF+MSC)] . 100\%, em que MG: massa do grão $\left(\mathrm{kg} \mathrm{ha}^{-1}\right)$, MSF: matéria seca da folha, MSC: matéria seca do colmo;

- Índice de colheita de nitrogênio (ICN), $\mathrm{ICN}=[\mathrm{NG} /(\mathrm{NG}+\mathrm{NC}+\mathrm{NF})] .100 \%$, em que NG:nitrogênio do grão $\left(\mathrm{kg} \mathrm{ha}^{-1}\right)$, NC: nitrogênio do colmo $\left(\mathrm{kg} \mathrm{ha}^{-1}\right)$, NF: nitrogênio da folha $\left(\mathrm{kg} \mathrm{ha}^{-1}\right)$;

- Nitrogênio Remobilizado (NR), $N R=\left(\mathrm{NA}_{1}\right.$ $\mathrm{NM})$, em que $\mathrm{NA}_{1}=$ nitrogênio da folha $\left(\mathrm{kg} \mathrm{ha}^{-1}\right)+$ nitrogênio do colmo $\left(\mathrm{kg} \mathrm{ha}^{-1}\right)$ na antese e $\mathrm{NM}=$ nitrogênio da folha $\left(\mathrm{kg} \mathrm{ha}^{-1}\right)+$ nitrogênio do colmo $\left(\mathrm{kg} \cdot \mathrm{ha}^{-1}\right)$ na maturação;

- Nitrogênio Acumulado (NA), NA= (NTM NTA), em que NTM= nitrogênio da folha + nitrogênio do colmo + nitrogênio do grão na maturação $\left(\mathrm{kg} \mathrm{ha}^{-}\right.$ ${ }^{1}$ ) e NTA = nitrogênio na folha + nitrogênio no colmo na antese; $\mathrm{e}$

- Proteína bruta (PB), $\mathrm{PB}=\mathrm{N} \%$ do grão $\times$ 6,25, em que $\mathrm{N} \%$ do grão: teor de nitrogênio no grão em percentagem e 6,25: fator de conversão de N\% para proteína bruta (Donald e Hamblim, 1976).

Para as análises de variância e de correlação dos dados utilizou-se o programa estatístico SAEG 8.0.

As leguminosas foram podadas a $50 \mathrm{~cm}$ do solo e os ramos adicionados nas entrelinhas da cultura do arroz, logo após a germinação das sementes, em 1996, 1997, 1998 e 1999 e nas entrelinhas do milho em 2001. Em 2000, o experimento foi deixado em pousio. Em 2001, não houve corte dos ramos de guandu e a leucena foi submetida à segunda poda aos
58 dias após o primeiro corte, em função da sua grande capacidade de rebrota e da possibilidade de sombreamento da cultura do milho (Tabela 1).

Em 2001, conforme o balanço de nutrientes no sistema, os teores de bases trocáveis estavam em níveis adequados nos tratamentos com sombreiro, leucena e guandu, segundo parâmetros de Ribeiro et al. (1999), devido, principalmente, às quantidades recicladas de cálcio e magnésio, e também à contribuição da leucena e do sombreiro para manutenção dos níveis de potássio. Com relação ao $\mathrm{P}$, determinaram-se mais quantidades adicionadas por adubação do que por reciclagem, porém, nesse caso, os reduzidos teores de argila do solo e a pouca mobilidade do elemento no perfil são fatores favoráveis à sua presença em níveis adequados na zona das raízes. No caso do nitrogênio constatou-se grande variação entre os teores com cultivo das leguminosas, com destaque para a leucena e o sombreiro com as quais obtiveram-se quantidades quase três vezes maiores do que nas outras duas espécies (Tabelas 2 e 3 ).

\section{RESULTADOS E DISCUSSÃO}

Houve grande variação temporal nos dados de massa vegetal produzida pelas leguminosas como apresentado na tabela 1 . As maiores diferenças foram constatadas no ingá, estabelecido apenas no terceiro ano e no guandu, com pico de produtividade no segundo e sem produção de brotação já no quinto ano. Para finalidade de cobertura de solo o sombreiro foi a leguminosa mais adequada, seguindo-se o ingá, tanto pela quantidade quanto pela permanência dos resíduos na superfície, constatada visualmente.

Tabela 1. Quantidade de massa vegetal seca em ramos podados de quatro leguminosas arbóreas em sistema de cultivo em aléias. São Luís (MA)

\begin{tabular}{lcccccc}
\hline Leguminosas & 1996 & 1997 & 1998 & 1999 & 2001 & Total \\
\cline { 2 - 6 } & \multicolumn{7}{c}{$\mathrm{mg} \mathrm{ha}^{-1}$} & & & \\
\cline { 2 - 6 } Guandu (Cajanus cajan) & $0,97 \mathrm{a}$ & $8,50 \mathrm{a}$ & $3,55 \mathrm{~b}$ & $2,43 \mathrm{c}$ & $0,00 \mathrm{~d}\left(\left(^{1}\right)\right.$ & 15,45 \\
Ingá (Inga edulis) & $0,00 \mathrm{~b}$ & $0,88 \mathrm{c}$ & $3,21 \mathrm{~b}$ & $3,27 \mathrm{c}$ & $4,95 \mathrm{c}$ & 12,31 \\
Leucena (Leucaena leucocephala) & $0,04 \mathrm{~b}$ & $3,50 \mathrm{~b}$ & $6,39 \mathrm{a}$ & $8,21 \mathrm{~b}$ & $6,61 \mathrm{~b}\left(\left(^{2}\right)\right.$ & 28,75 \\
Sombreiro (Clitoria fairchildiana) & $0,22 \mathrm{~b}$ & $6,98 \mathrm{a}$ & $7,64 \mathrm{a}$ & $12,40 \mathrm{a}$ & $10,82 \mathrm{a}$ & 38,06 \\
CV (\%) & 15,0 & 13,0 & 10,0 & 12,0 & 15,0 & - \\
\hline
\end{tabular}

Letras diferentes na mesma coluna não são indicativas de diferença significativa ao nível de $5 \%$ pelo teste de Tukey.

( ${ }^{1}$ Plantas sem brotação e sem poda.

$\left({ }^{2}\right)$ Duas podas; excesso de rebrote. 
Tabela 2. Análise de um Argissolo Vermelho-Amarelo, distrófico, textura franco-arenosa, em área experimental com aléias de leguminosas arbóreas. São Luís (MA)

\begin{tabular}{|c|c|c|c|c|c|c|c|}
\hline \multirow{2}{*}{ Leguminosas } & \multicolumn{7}{|c|}{ Antes da implantação do experimento $\left({ }^{1}\right)$} \\
\hline & $\mathrm{pH}$ & $\mathrm{MO}$ & $\mathrm{P}$ & $\mathrm{Ca}$ & $\mathrm{Mg}$ & K & N-total \\
\hline & $\mathrm{CaCl}_{2}$ & $\mathrm{~g} \mathrm{~kg}^{-1}$ & $\mathrm{mg} \mathrm{dm} \mathrm{m}^{-3}$ & \multicolumn{3}{|c|}{$\mathrm{mmol}_{\mathrm{c}} \mathrm{dm}^{-3}$} & $\mathrm{~g} \mathrm{~kg}^{-1}$ \\
\hline Guandu (Cajanus cajan) & 4,72 & 26,4 & 5,7 & 21,4 & 7,9 & 0,9 & 0,86 \\
\hline Ingá (Inga edulis) & 4,56 & 27,3 & 2,6 & 15,5 & 9,8 & 0,9 & 0,76 \\
\hline Leucena (Leucaena leucocephala) & 4,41 & 25,5 & 2,5 & 18,2 & 8,8 & 0,6 & 0,84 \\
\hline Sombreiro (Clitoria fairchildiana) & 4,4 & 28,2 & 3,8 & 17,3 & 9,6 & 0,9 & 0,80 \\
\hline Testemunha & 4,32 & 25,1 & 3,0 & 18,3 & 9,6 & 0,7 & 0,85 \\
\hline \multirow{3}{*}{ Leguminosas } & \multicolumn{7}{|c|}{ Após cinco anos de adição dos ramos de leguminosas $\left({ }^{2}\right)$} \\
\hline & $\mathrm{pH}$ & $\mathrm{MO}$ & $\mathrm{P}$ & $\mathrm{Ca}$ & $\mathrm{Mg}$ & K & N-total \\
\hline & $\mathrm{CaCl}_{2}$ & $\mathrm{~g} \mathrm{~kg}^{-1}$ & $\mathrm{mg} \mathrm{dm} \mathrm{m}^{-3}$ & \multicolumn{3}{|c|}{$\mathrm{mmol}_{\mathrm{c}} \mathrm{dm}^{-3}$} & $\mathrm{~g} \mathrm{~kg}^{-1}$ \\
\hline Guandu (Cajanus cajan) & 5,1 & 38,0 & 11,7 & 31,5 & 11,8 & 3,1 & 17,3 \\
\hline Ingá (Inga edulis) & 5,1 & 38,6 & 11,6 & 22,4 & 11,2 & 1,6 & 22,5 \\
\hline Leucena (Leucaena leucocephala) & 5,0 & 53,0 & 11,2 & 27,6 & 13,4 & 3,2 & 26,5 \\
\hline Sombreiro (Clitoria fairchildiana) & 5,0 & 44,6 & 12,8 & 28,4 & 14,6 & 3,0 & 24,5 \\
\hline Testemunha & 5,2 & 26,3 & 8,5 & 23,5 & 10,6 & 2,2 & 18,0 \\
\hline
\end{tabular}

(1) Janeiro de 1996. $\left({ }^{2}\right)$ Junho de 2001.

Tabela 3. Nutrientes reciclados por leguminosas em aléias e adicionados pela adubação mineral de 1996 a 2001 . São Luís (MA)

\begin{tabular}{|c|c|c|c|c|c|}
\hline Leguminosas & $\mathrm{N}$ & $\mathrm{P}$ & K & $\mathrm{Ca}$ & $\mathrm{Mg}$ \\
\hline & & 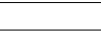 & $\mathrm{kg} \mathrm{ha}^{-1}$ & & \\
\hline Guandu (Cajanus cajan) & 385,9 & 21,3 & 119,8 & 185,5 & 38,9 \\
\hline Ingá (Inga edulis) & 408,7 & 22,1 & 283,6 & 76,5 & 33,7 \\
\hline Leucena (Leucaena leucocephala) & 1261,9 & 68,1 & 688,6 & 161,8 & 131,1 \\
\hline Sombreiro (Clitoria fairchildiana) & 1189,8 & 68,1 & 934,7 & 248,9 & 119,5 \\
\hline Adicionado pela adubação mineral & 156 & 111,3 & 103,7 & 204,5 & - \\
\hline
\end{tabular}

Tanto por ocasião da antese quanto da maturidade com as leguminosas sombreiro e ingá, foram proporcionadas mais produções de matéria seca nas folhas e nos colmos do milho, em relação à leucena e ao guandu; com estas as produções de matéria seca no milho não foram diferentes da testemunha sem leguminosas (Tabela 4). Esse fato significa que não foi relevante o sincronismo entre a liberação do $\mathrm{N}$ derivado da adição dos resíduos de leguminosas e a demanda pela cultura intercalar, pois, com aporte do dobro de $\mathrm{N}$ pela leucena, em relação ao ingá, no ano do cultivo do milho, não se obteve aumento correspondente na matéria seca da cultura. Assim, a utilização de resíduos de alta qualidade, ou seja, aqueles que possuem elevados teores de $\mathrm{N}$ e pequenas quantidades de lignina e polifenóis e com grande taxa de decomposição pode não ser a melhor escolha em solos arenosos, em situações de grande precipitação pluvial.

Moura (1995), trabalhando em condições similares concluiu que na predominância da fração areia fina e com elevada precipitação pluvial é diminuída a porosidade efetiva do solo descoberto, principal fator determinante do decréscimo da produtividade da cultura do milho, nessas condições. Portanto, com a permanência dos resíduos do ingá e do sombreiro deve ter sido favorecida a proteção do solo, permitindo-se mais capacidade de aeração e conseqüentemente maior aproveitamento do fertilizante nitrogenado aplicado. A importância dessa propriedade física pode ser mais bem avaliada considerando-se que, no mês de enchimento dos grãos, registrou-se índice pluviométrico de $596 \mathrm{~mm}$. 
Tabela 4. Produtividade média de massa vegetal seca na antese e na maturidade de duas cultivares de milho (AG 405 e BR 106), cultivadas em aléias de quatro espécies de leguminosas. São Luís (MA), 2001

\begin{tabular}{|c|c|c|c|c|}
\hline \multirow{2}{*}{ Tratamentos } & \multicolumn{2}{|c|}{ ANTESE } & \multicolumn{2}{|c|}{ MATURAÇÃO } \\
\hline & Folha & Colmo & Folha & Colmo \\
\hline & & 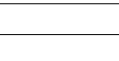 & & \\
\hline Guandu (Cajanus cajan) & $1,30 \mathrm{~b}$ & $2,21 \mathrm{ab}$ & $1,59 \mathrm{ab}$ & $1,78 \mathrm{a}$ \\
\hline Ingá (Inga edulis) & $1,54 \mathrm{ab}$ & $2,65 \mathrm{a}$ & $1,84 \mathrm{a}$ & $2,35 \mathrm{a}$ \\
\hline Leucena (Leucaena leucochephala) & $1,30 b$ & 2,19ab & $1,64 \mathrm{ab}$ & $1,96 a$ \\
\hline Sombreiro (Clitoria fairchildiana) & $1,61 \mathrm{a}$ & $2,71 \mathrm{a}$ & $1,72 \mathrm{ab}$ & $2,12 \mathrm{a}$ \\
\hline Testemunha & $1,16 \mathrm{c}$ & $1,97 b$ & $1,36 \mathrm{~b}$ & $1,65 a$ \\
\hline CV $(\%)$ & 10,0 & 11,0 & 10,0 & 12,0 \\
\hline
\end{tabular}

Valores seguidos por letras iguais na mesma coluna não são diferentes significativamente entre si ao nível de 5\% pelo Teste Tukey

Foram constatadas diferenças acentuadas nas variações na matéria seca das fontes (folhas e colmos), entre a antese e a maturidade, com mais reduções nos tratamentos sem adição de resíduos $-6,6 \%$ para o guandu e $4,2 \%$ para a testemunha, comparadas à redução nas parcelas com resíduos de sombreiro $1,2 \%$ e de ingá $0,2 \%$. Nas parcelas com resíduos de leucena, houve aumento de $4,1 \%$, que pode ser atribuído ao aporte adicional de resíduos pelo segundo corte dessa leguminosa (Tabela 4), em virtude de sua grande capacidade de rebrota, com provável influência nos níveis de $\mathrm{N}$ disponíveis nessa fase. Segundo $\mathrm{V}_{\text {AN }}$ Der MEersch et al. (1993) há mais sincronização entre o N liberado pela leucena e aquele absorvido pelo milho, após a segunda poda, comparando-se ao $\mathrm{N}$ fornecido pela primeira poda. Eles também constataram que a pequena quantidade de $\mathrm{N}$ recuperado da primeira poda não é necessariamente excluída do sistema, pois pode ser recuperada pelas aléias ou imobilizada na matéria orgânica do solo.

Segundo Yoshida (1972), a contribuição em carboidratos armazenados para o enchimento dos grãos é dependente dos níveis de $\mathrm{N}$ disponíveis nessa fase. Se estiverem em quantidades adequadas, é favorecida a atividade fotossintética, tornando a partição de carboidratos para os grãos menos dependente da matéria seca acumulada até a antese.

Os desempenhos dos genótipos AG 405 e BR 106 de milho foram semelhantes quanto à partição $\mathrm{e}$ acumulação de $\mathrm{C}$ e $\mathrm{N}$, não sendo diferentes quanto ao teor de proteína bruta (PB), ao índice de colheita (IC), índice de colheita de $\mathrm{N}$ (ICN), $\mathrm{N}$ remobilizado (NR) e ao $\mathrm{N}$ acumulado (NA) (Tabela 5). Com a adição de resíduos de leguminosas não foram negativamente afetados o IC e o NR, mas sim os teores de PB, o de ICN e de NA. O IC é um parâmetro genético, que não deve ser influenciado pelo aporte de N (Donald e HAMBLIM, 1976).

Com os resíduos das leguminosas a partição de $\mathrm{N}$ foi afetada de forma diferenciada. Nas parcelas com adição de resíduos de leucena e de ingá os valores de $\mathrm{PB}, \mathrm{ICN}$ e NA formas elevados e, provavelmente, o N fornecido na segunda poda da leucena, por ocasião da antese, foi direcionado ao grão. Em vários trabalhos foi demonstrado serem os grãos o dreno preferencial para o $\mathrm{N}$ fornecido pós-antese (FERRAZ JúNIOR. et al., 1999; SouZA et al., 1998). Resultados semelhantes são comuns e coincidentes com dados na literatura mundial, sendo o principal motivo para se iniciar um esforço global para aumento da eficiência do uso do $\mathrm{N}$.

Tabela 5. Proteína bruta (PB); índice de colheita (IC); índice de colheita de N (ICN), nitrogênio remobilizado (NR) e nitrogênio acumulado (NA) em plantas de milho, cultivadas em aléias de quatro leguminosas. São Luís (MA), 2001

\begin{tabular}{lccccc}
\hline TRATAMENTOS & P.B. & I.C. & I.C.N & N.R. & N.A. \\
\hline & & & & & \\
Guandu (Cajanus cajan) & $9,82 \mathrm{~b}$ & $59,92 \mathrm{a}$ & $73,31 \mathrm{ab}$ & $25,77 \mathrm{a}$ & $33,12 \mathrm{~b}$ \\
Ingá (Inga edulis) & $11,47 \mathrm{a}$ & $60,5 \mathrm{a}$ & $76,16 \mathrm{ab}$ & $37,50 \mathrm{a}$ & $52,51 \mathrm{ab}$ \\
Leucena (Leucaena leucochephala) & $11,29 \mathrm{a}$ & $63,82 \mathrm{a}$ & $78,35 \mathrm{a}$ & $27,68 \mathrm{a}$ & $61,67 \mathrm{a}$ \\
Sombreiro (Clitoria fairchildiana) & $10,65 \mathrm{ab}$ & $60,44 \mathrm{a}$ & $70,94 \mathrm{~b}$ & $36,83 \mathrm{a}$ & $47,69 \mathrm{ab}$ \\
Testemunha & $10,14 \mathrm{ab}$ & $60,98 \mathrm{a}$ & $75,01 \mathrm{ab}$ & $22,83 \mathrm{a}$ & $34,68 \mathrm{~b}$ \\
CV $(\%)$ & 12 & 13 & 11 & 15 & 15 \\
\hline
\end{tabular}

Valores seguidos por letras iguais na mesma coluna não são diferentes significativamente entre si ao nível de $5 \%$ pelo Teste Tukey. 
Uma das desvantagens do sistema em aléias é a possibilidade da competição entre as árvores e a cultura, evidenciada pela menor produtividade nas linhas adjacentes às fileiras das árvores, como constatado por Jose et al., (2006). Neste experimento constatou-se uma tendência para obtenção de maiores valores de massa de mil grãos e de produtividade nas linhas adjacentes, comparadas às linhas centrais, sugerindo-se a não-existência de competição interespecífica (milho x leguminosa) e efeito da liteira produzida pela derrubada das folhas no período seco (Tabela 6). Embora sem diferenças estatísticas entre si, esses resultados são assemelhados aos de AKINNIFESI et al. (1996), que ao estudarem a competição entre leucena e o milho, concluíram ser mais eficiente a utilização do $\mathrm{N}$ por plantas de milho desenvolvidas adjacentemente às aléias de leucena, na estação chuvosa; o contrário foi verificado durante a estação seca. Como se verifica, na ausência de competição por água e luz, como foi no caso deste experimento, a tendência é a utilização, pela cultura adjacente às leguminosas, do maior volume de liteira nesta área, com conseqüente crescimento igual ou superior ao constatado nas fileiras centrais.

Tabela 6. Produtividade de grãos e massa de 1000 grãos de quatro espécies de leguminosas na produtividade de grãos nas linhas da cultura do milho. São Luís (MA), 2001

\begin{tabular}{|c|c|c|c|c|c|}
\hline \multirow{2}{*}{ Tratamentos } & \multicolumn{5}{|c|}{ Produtividade de grãos $\left(\mathrm{Mg} \mathrm{ha}^{-1}\right)$} \\
\hline & L1 & $\mathrm{L} 2$ & L3 & $\mathrm{L} 4$ & $\mathrm{XL}$ \\
\hline Guandu (Cajanus cajan) & $4,31 A a$ & $3,81 \mathrm{Ba}$ & $3,72 A B a$ & $4,54 A a$ & $4,09 \mathrm{~b}$ \\
\hline Ingá (Inga edulis) & $5,72 \mathrm{Aa}$ & $5,67 \mathrm{Aa}$ & $5,67 \mathrm{Aa}$ & $5,23 \mathrm{Aa}$ & 5,66 a \\
\hline Leucena (Leucaena leucocephala) & $5,26 \mathrm{Aa}$ & $5,78 \mathrm{Aa}$ & $5,67 \mathrm{Aa}$ & $5,71 \mathrm{Aa}$ & $5,60 \mathrm{a}$ \\
\hline Sombreiro (Clitoria fairchildiana) & $5,84 \mathrm{Aa}$ & $6,11 \mathrm{Aa}$ & $5,80 \mathrm{Aa}$ & $5,50 \mathrm{Aa}$ & 5,81 a \\
\hline Testemunha & $4,40 \mathrm{Aa}$ & 3,35 Bab & $3,02 \mathrm{Bb}$ & $4,41 \mathrm{Aa}$ & $3,79 \mathrm{~b}$ \\
\hline XG & $5,11 \mathrm{~A}$ & $4,95 \mathrm{~A}$ & $4,77 \mathrm{~A}$ & $5,14 \mathrm{~A}$ & - \\
\hline $\mathrm{CV}(\%)$ & 10,0 & 11,0 & 11,0 & 12,0 & - \\
\hline \multirow{2}{*}{ Tratamentos } & \multicolumn{5}{|c|}{ Massa 1000 grãos (g) } \\
\hline & L1 & $\mathrm{L} 2$ & L3 & $\mathrm{L} 4$ & $\mathrm{XL}$ \\
\hline Guandu (Cajanus cajan) & $288,48 A a$ & $267,94 B a$ & $273,63 A a$ & $287,08 A a$ & $279,28 b$ \\
\hline Ingá (Inga edulis) & $323,80 \mathrm{Aa}$ & 316,99Aa & $319,62 \mathrm{Aa}$ & $313,14 \mathrm{Aa}$ & $318,39 a$ \\
\hline Leucena (Leucaena leucocephala) & $312,87 \mathrm{Aa}$ & $322,79 \mathrm{Aa}$ & $318,77 \mathrm{Aa}$ & $312,18 \mathrm{Aa}$ & $316,65 a$ \\
\hline Sombreiro (Clitoria fairchildiana) & $332,57 \mathrm{Aa}$ & $327,60 \mathrm{Aa}$ & $332,50 \mathrm{Aa}$ & $325,98 \mathrm{Aa}$ & $329,66 a$ \\
\hline Testemunha & $284,61 \mathrm{Aa}$ & $254,27 \mathrm{Ca}$ & $258,82 \mathrm{Ba}$ & $294,23 \mathrm{Aa}$ & $272,99 b$ \\
\hline XG & $308,47 \mathrm{~A}$ & $297,92 \mathrm{~A}$ & $300,67 \mathrm{~A}$ & $306,52 \mathrm{~A}$ & - \\
\hline $\mathrm{CV}(\%)$ & 14,0 & 12,0 & 15,0 & 10,0 & - \\
\hline
\end{tabular}

$\mathrm{XL}=$ média das leguminosas; $\mathrm{XG}=$ média dos genótipos; $\mathrm{L} 1$ e L4, distantes $0,5 \mathrm{~m}$ das linhas das leguminosas; L2 e L3 distantes 1,5m das linhas das leguminosas

*Letras maiúsculas se referem à diferença entre valores de tratamentos nas colunas e letras minúsculas à diferença entre linhas de milho nas linhas. Médias seguidas da mesma letra não são diferentes entre si $(\mathrm{P}<0,05)$, segundo o teste de Tukey.

A produtividade de grãos do híbrido AG 405 foi superior à do BR 106, em todos os tratamentos (Figura 1). Considerando-se que nos dois genótipos os IC e as quantidades de matéria seca foram semelhantes, essa diferença positiva em AG 405 é reflexo de sua maior capacidade como dreno reprodutivo, evidenciado na maior massa de mil grãos - 327g, em relação à do BR 106 - 280g, valor semelhante (328g) para o AG 405 constatado por SILVA et al., (1996). Para o BR 106, Aguiar e Moura (2003), reportaram valor de 231 g para experimento desenvolvido no mesmo solo. Com a adição dos ramos de ingá, leucena e de sombreiro, aumentou-se a produtividade nos dois genótipos, mas no híbrido AG 405 , os valores foram bem superiores aos da variedade BR 106. A massa de mil grãos foi o fator de maior contribuição para as diferenças na produtividade de grãos, sendo favorecida pelas adições de resíduos de leguminosas no ano do cultivo do milho. Embora não avaliados alguns fatores relacionados na literatura podem ter contribuído para o estabelecimento dessas diferenças em produtividade, como: a capacidade de dreno reprodutivo (MARSCHNER, 1986); absorção de N antes e após a antese; a duração da fase de enchimento dos grãos; a taxa de síntese de enzimas afetadas pela adubação nitrogenada; as diferenças na 
cinética de absorção de $\mathrm{N}$; e a cinética de enchimento dos grãos (TsAi et al., 1983). Esses autores reportaram que as diferenças nas taxas e no tempo de acumulação de matéria seca entre dois híbridos de milho, podem ser atribuídas à cinética de absorção de N. No presente trabalho, determinou-se correlação positiva e muito significativa entre a produtividade de grãos e as quantidades de $\mathrm{N}$ total nas folhas das plantas de milho por ocasião da antese - 0,5777 , e as quantidades de K nas folhas por ocasião da maturação - 0,8267. A massa do grão é geneticamente controlada e dependente de fatores ambientais os quais têm influência nos processos de enchimento durante a maturação.

No processo de enchimento dos grãos, a espiga ou os grãos são drenos fisiológicos e a intensidade desse dreno é muito dependente do número de células no seu endosperma; ainda, o $\mathrm{K}$ tem uma influência benéfica no desenvolvimento dessas células, na translocação de fotoassimilados do floema para o grão e, portanto, na massa do grão (MARSCHNER, 1986). Em relação ao N, com sua absorção na préantese são aumentados o comprimento da espiga e o número de espiguetas férteis (SCHREIBER et al., 1988).

A produtividade de grãos nas parcelas sob o efeito residual da adição de ramos de guandu nos anos anteriores, não foi diferente daquela na testemunha sem aléias. Significa que o efeito residual de ramos aplicados em anos anteriores, com efeitos positivos na manutenção dos teores de matéria orgânica e de alguns macronutrientes, promovidos pela adição do guandu, entretanto foi menos determinante que a cobertura do solo propiciada pelo ingá para a produtividade de grãos na cultura do milho.

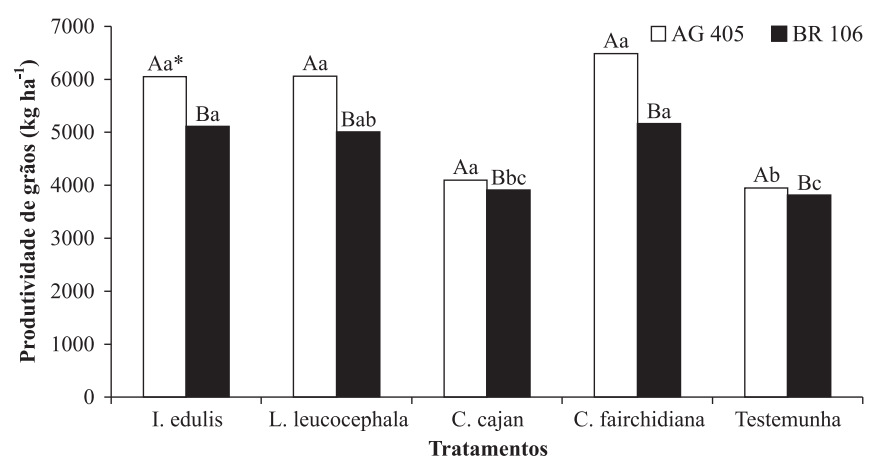

Figura 1. Produção de grãos de dois genótipos de milho cultivados em aléias de quatro espécies de leguminosas. São Luís (MA), 2001.

*Letras maiúsculas se referem a diferença entre genótipos e letras minúsculas à diferença entre tratamentos. Médias seguidas da mesma letra não são diferentes entre si $(P<0,05)$, segundo o teste de Tukey.

\section{CONCLUSÕES}

1. O sistema de aléias com leguminosas arbóreas é uma alternativa importante ao manejo sustentável dos agroecossistemas no tropico úmido, devendo ser considerada a capacidade de cobertura do solo e a reciclagem dos nutrientes potássio, cálcio e nitrogênio.

2. No trópico úmido a produtividade em grãos na cultura do milho é favorecida no sistema de aléias preestabelecidas com as leguminosas arbóreas sombreiro, ingá e leucena e pela utilização de genótipos eficientes no aproveitamento do nitrogênio, cujo sincronismo entre a liberação e a absorção do N aplicado por meio das leguminosas deve ser aprimorado.

\section{REFERÊNCIAS}

AGUIAR, A.C.F.; MOURA, E.G. Crescimento e produtividade de duas cultivares de milho de alta qualidade protéica em solo de baixa fertilidade. Bragantia, Campinas, v.62, n.3, p.429435, 2003.

AKINNIFESI, F. K.; KANG, B. T.; SANGINGA, N.; TIJANI ENIOLA, $\mathrm{H}$. Nitrogen use efficiency and $\mathrm{N}$ - competition between Leucaena hedgerows and maize in an alley cropping system. Nutrient Cycling in Agroecosystems, Berlin, v.47, n.1, p.71-80, 1996.

ALBUQUERQUE, J.M. Níveis de preparo e de cobertura entre aléias de guandu com milho, como alternativas de melhoramento da qualidade física e do uso intensivo de um Argissolo da Formação Itapecuru-MA. 1999. 66f. Dissertação (Mestrado em Agroecologia) - Universidade Estadual do Maranhão, São Luís.

ATTA-KRAH, A. N. Alley farming with leucaena: effects of short grazed fallows on soil fertility and crop yields. Experimental Agriculture, Cambridge, v.1, n.20, p.1-10, 1989.

DONALD, C.M.; HAMBLIN, J. The biological yield and harvest index of cereals as agronomic and plant beeding criteria. Advances in Agronomy, San Diego, v.4, n. 28, p. 361- 405, 1976.

FERRAZ JUNIOR, A.S.L.; SOUZA, S.R.; FERNANDES, M.S. Ciclagem de nutrientes em sistema de cultivo em aléias. Pesquisa em Foco, São Luís, v.5, n.6, p. 7-29, 1999.

FERRAZ JUNIOR, A.S.L. O cultivo em aléias como alternativa para a produção de alimentos na agricultura familiar do trópico úmido. In: MOURA, E.G. (Ed.). Agroambientes de transição: entre o trópico úmido e o semi-árido do Brasil. São Luís: Universidade Estadual do Maranhão, 2004. cap.3, p. 71-100.

HUANG, W.Y.; SHNK, D.; HEWITT, T.I. On-farm costs of reducing residual nitrogen on cropland vulnerable to nitrate leaching. Review Agriculture Economy, New York, v.3, n.18, p.325-339, 1996. 
KANG, B.T.; REYNOLDS, L.; ATTA-GRAH, A.N. Alley farming. Advances in Agronomy, New York, v.4, n. 43, p.315$359,1990$.

JOSE, S.; WILLIAMS, R.; ZAMORA, D. Belowground ecological interactions in mixed-species forest plantations. Forest Ecology and Management, v.233, n.2, p.231-239, 2006.

MARSCHNER, H. Mineral nutrition of higher plants. San Diego: Academic Press, 1986. 389p.

MOURA, E. G. Atributos de fertilidade de um podzólico vermelho amarelo da formação Itapecuru limitantes da produtividade do milho. 1995. 82f. Tese (Doutorado em Agronomia/Irrigação e Drenagem) - Faculdade de Ciências Agronômicas, Universidade Estadual Paulista, Botucatu.

RIBEIRO, A.C.; GUIMARÃES, P.T.G.; ALVAREZ, V.H.V. (Ed.). Recomendações para o uso de corretivos e fertilizantes em Minas Gerais - 5 a Aproximação. Viçosa: Universidade Federal de Viçosa, 1999. 359p.

SCHREIBER, H.A.; STANBERRY, C.O.; TUCKER, H. Irrigation and nitrogen effects on sweet corn row numbers at various growth stages. Science, Washington, v.9, n. 135, p.1135-1136, 1988.

SLVA, P.S.L.; BARRETO, H.E.P.; SANTOS, M.X. Avaliação de cultivares de milho quanto aos rendimentos de grãos verdes e secos. Pesquisa Agropecuária Brasileira, v.10, n.5, p.125-130, 1996.

SOUZA, S.R.; STARK, E.M.L.; FERNANDES, M.S. Nitrogen remobilization during the reproductive period in two brazilian rice varieties. Journal of Plant Nutrition, Madison, v.10, n.21, p.2049-2063, 1998.

SWIFT, M. J.; PALM, C. A. Evaluation of the potencial contribuition of organic sources of nutrients to crop growth. In: Integrated plant nutrition systems. DUDAL, R.; ROY, R.N. (Eds.). Roma: FAO, 1995. p.171-180.

TEDESCO, M.J. Extração simultânea de N, P, K, Ca e Mg em tecido de planta por digestão por $\mathrm{H}_{2} \mathrm{O}_{2}-\mathrm{H}_{2} \mathrm{SO}_{4}$. Porto Alegre: UFRGS. 1982. 102p. (Apostila Informativo interno)

TSAI, C.Y.; WARREN, H.L. HUBBER, D.M.; BRESSAN, R.A. Interactions between the Kernel $\mathrm{N}$ sink, grain yield and protein nutrional quality of maize. Journal Science Food Agriculture, New York, v.2, n.34, p.255-263, 1983.

VAN DER MEERSCH, M.K.; MERCKX, R.; MULONGOY, K. Evolution of plant biomass and nutrition content in relation to soil fertility changes in two alley cropping systems. In: MULONGOY, K; MERCKX, R. (Ed.). Soil Organic Matter Dynamics and Sustainability of Tropical Agriculture. Johnwiley: Chichester, 1993. cap. 3, p. 143-154.

VARVEL, G.E. Monoculture and rotation system effects on precipitation use efficiency in corn. Agronomy Journal, Madison, v.86, n.3, p.204-208, 1994.

YOSHIDA, S. Physiological aspects of grain yield. Annual Review Plant Physiology, New York, v.23, n.5, p.437-464, 1972. 